It would no doubt be of great assistance to teachers who have had little experience with visually limited children; there is little to interest an ophthalmologist, but a few might be interested to read of the way in which different visual disabilities produce different behaviour in the classroom.

Recommended Aids for the Partially Sighted. By L. L. SloAN. Revised 2nd ed., I97I. Pp. 64, figs, refs. National Society for the Prevention of Blindness, Inc., New York. (\$2.00)

A factual description of the techniques and optical principles of visual aid dispensing. The commonly used devices are described and their relative merits discussed. (This is a very useful handbook for those concerned in visual aid practice.)

Lecture Notes on Ophthalmology. By P. D. Trevor-Roper. $4^{\text {th }}$ ed., I97 I. Pp. I04, 78 figs. Blackwell Scientific Publications, Oxford. ( $($ I.25)

This tiny book still manages to contain, in Ioo small pages, the basic requirements of ophthalmological knowledge for the medical student. It can be unhesitatingly recommended for this purpose.

Advances in Ophthalmology. Vol. 24. Edited by M. J. Roper-Hall, H. Sautter, and E. B. Steriff. I971. Pp. 382, 8o figs, i col. pl., bibl. Karger, Basel. (£i 2.15) In this latest volume of the Advances, Barraquer and Rutllàn review the advances in cataract surgery from 1957 to 1967 , Cordier, Reny, and Kahn review the ocular signs of trisomy 13, Baurmann discusses some basic problems in fluorescence angiography of the fundus, Scouras presents sixteen cases of intraepithelial epithelioma (Bowen), and Sévin discusses the pathogenesis of diabetic retinopathy.

These articles are of the usual high standard that we have come to expect from Advances and can be recommended to those interested in these particular topics.

\title{
The Perception and Application of Flashing Lights.
}

J. G. Holmes (Chairman). I97I. Pp. 429, figs, refs. Adam Hilger, London. (£7.00) These are the proceedings of an international symposium held at Imperial College, London, under the joint auspices of the National Illumination Committee of Great Britain and the Applied Optics Section, Imperial College, on April 19 to 22, 197 I, at which 33 papers were presented by authoritative speakers and were fully discussed. Many of the sessions were devoted to the application of flashing lights to conditions pertaining to land, sea, and air, and the book is recommended to all those interested in such matters.

\section{Notes}

\section{Toronto General Hospital}

Refresher Course, April io and I I, 1972

The subject of the course to be held at the Toronto Hospital for Sick Children will be "Surgery of the Cornea and Cataract Extraction". The guests of honour are:

Dr. Richard C. Troutman (State University of New York);

Mr. Anthony J. Bron (Institute of Ophthalmology, London, England);

Dr. Claes H. Dohlman (Retina Foundation, Boston, Mass.). 